\title{
VALORIZAÇÃO DE PERSONAGENS NEGROS COMO CONTEÚDO CURRICULAR NO LIVRO DIDÁTICO DE HISTÓRIA
}

\section{APPRECIATION OF BLACK CHARACTERS AS CURRICULUM CONTENT PRESENT IN TEXTBOOKS OF HISTORY}

\author{
ROZA, Luciano Magela \\ lucianoroza@gmail.com \\ UFVJM - Universidade Federal dos Vales do Jequitinhonha e do Mucuri
}

\begin{abstract}
RESUMO O artigo busca discutir alguns aspectos da incorporação e da apropriação da valorização de personagens negros como conteúdo curricular presente em livros didáticos de história editados no contexto pós-lei 10.639/03. Algumas das coleções didáticas, aprovadas e reeditadas no Programa Nacional do Livro Didático (PNLD) nos anos 2008 e 2011, são privilegiadas como material empírico, em especial, os conteúdos explícitos e as atividades sugeridas para o ensino-aprendizagem da história afro-brasileira no pósabolição presentes livro do aluno.
\end{abstract}

PALAVRAS-CHAVE: Lei 10.639/03. Livros didáticos. Ensino de História. História afro-brasileira.

\section{ABSTRACT}

The paper aims to discuss some aspects of incorporation and ownership of the appreciation of black characters as curriculum content present in textbooks of history in post-edited Law 10.639 / 03 context. Some of the teaching, approved and reissued in the National Textbook Program (NPDB) in the years 2008 and 2011, collections are privileged as empirical material, in particular, the explicit content and suggested activities for teaching-learning of african-Brazilian history in postabolition present student textbook.

KEYWORDS: Law 10.639/03; Textbooks; History Teaching; Afro-brazilian History.

\section{INTRODUÇÃO}

A política educacional empreendida pela Lei $n^{0} 10.639 / 03$, ao tornar obrigatório o ensino da História e cultura africana e afro-brasileira nas 
instituições do Ensino Básico no Brasil, assim como as Diretrizes Curriculares Nacionais para a Educação das Relações Étnico-Raciais e para o Ensino de História e Cultura Afro-brasileira e Africana, que criam e sugerem parâmetros, perspectivas de abordagem e de encaminhamentos didáticos para a implementação da referida lei, trouxeram para o contexto escolar a proposição do reposicionamento dos negros na história do Brasil. Tal reposicionamento, em contraposição e em combate à produção e circulação de representações subalternizadas, assim como o apagamento histórico de indivíduos e grupos de pertencimento étnico-racial de origem africana, dar-se-á pelo nãoesquecimento de suas ações, presença e contribuições, devendo assim serem lembradas, e também pela visibilidade de representações positivadas acerca de tais sujeitos históricos.

A Lei $10.639 / 03$, como política a ser implementada, trouxe para a ambiência escolar novas questões e desafios, bem como possibilidades de novas experiências e perspectivas de ordem política, pedagógica e historiográfica, destacando-se a possibilidade de criação de uma política de representação acerca do passado da população negra no Brasil, assim como trazer à tona histórias e memórias afro-brasileira outrora legadas ao esquecimento. Evidencia-se, assim, a presença negra como parte constitutiva da memória histórica e da história nacional, uma demanda por inclusão sem homogeneização.

$\mathrm{Na}$ tentativa de criar estratégias para a recepção da referida política educacional, um dos territórios acionados pelo poder público foi a produção didática voltada para a escolarização básica, mais precisamente, a produção de livros didáticos avaliada e distribuída pelo Programa Nacional do Livro Didático (PNLD). Contudo, a recepção de políticas públicas, assim como das diversas prescrições curriculares e legais, não ocorre tal como sugerida pelas instâncias institucionais proponentes. Geralmente, a recepção é fruto de um amplo processo de apropriação do conteúdo e das ações proposta. Considerando essa assertiva, este texto busca discutir, como um dos aspectos em torno da obrigatoriedade do ensino da história e cultura africana e afrobrasileira, como a valorização de personagens negros vem sendo incorporada 
como conteúdo curricular em livros didáticos de história produzidos pós-Lei 10.639/03. Na primeira parte do texto, buscamos problematizar diferentes aspectos da política educacional em foco, em especial, aqueles relacionados à história escolar, área disciplinar a qual pertence os livros analisados. $\mathrm{Na}$ segunda parte, dialogamos com autores que procuram compreender a natureza dos livros didáticos.

$\mathrm{Na}$ terceira parte, apresentamos alguns resultados de pesquisa que teve como objeto a abordagem da história afro-brasileira pós-abolição. A investigação teve como suporte algumas coleções didáticas aprovadas e reeditadas nos PNLD 2008 e 2011. O foco investigativo selecionado foram os conteúdos curriculares dos manuais escolares em que afro-brasileiros ou ações relacionadas a eles são tratadas. Buscou-se, assim, compreender as tensões entre saber escolar, a constituição de memórias e a proposta de política de representação em torno da temática em questão.

\section{ALGUNS ASPECTOS DA OBRIGATORIEDADE DO ENSINO DE HISTÓRIA E CULTURA AFRO-BRASILEIRA E AFRICANA}

No contexto da ampliação dos direitos de cidadania no país, no qual uma crescente sensibilidade pública acerca da compreensão de que o racismo existente na sociedade brasileira trata-se de uma questão socialmente viva, associada à concepção de que a escola seja uma dos espaços potentes para o combate a práticas discriminatórias tornam-se presentes. A Lei 10.639/03 trouxe para centro do debate educacional a emergência de uma proposta que compreende o viés da pluralidade cultural, que opta pela explicitação do particularismo étnico-racial como perspectiva articuladora das ações. Neste sentido, a legislação educacional em foco, além de tornar obrigatório o ensino sobre história e cultura afro-brasileira nos estabelecimentos de ensino fundamental e médio, oficiais e particulares, alterando a Lei de Diretrizes e Bases da Educação (Lei 9.394/96), inclui o dia 20 de novembro como "Dia Nacional da Consciência Negra" no calendário escolar, provocando um deslocamento da forma como temáticas étnico-raciais eram tratadas por meio 
da ideia de diversidade cultural tal como apresentada anteriormente pelos PCN voltados para o tema transversal da pluralidade cultural. O que se observa a partir da referida lei é a proposta de compreensão da sociedade brasileira em suas múltiplas temporalidades, que apresenta em sua centralidade, o pertencimento étnico-racial negro como eixo norteador, sem o qual a compreensão da sociedade brasileira se faz incompleta e problemática.

Apesar da obrigatoriedade da mudança curricular realizada pela Lei 10.639/03, as diretrizes que a implementam apresentam perspectivas de normatização marcadas pela flexibilidade e pela pluralidade de possibilidades sugeridas.

Nas Diretrizes Curriculares Nacionais para a Educação das Relações Étnico-Raciais e para o Ensino de História e Cultura Afro-brasileira e Africana é proposto um conjunto relativamente vasto de conteúdos, encaminhamentos pedagógicos e políticos e referências para o desenvolvimento de práticas docentes. Assim como de propostas de estruturação do currículo escolar, voltados para a problematização da educação étnico-raciais e da criação de estratégias e ações que visam a reconfiguração positiva, não-hierarquizada e simétrica de tais relações. O documento, apresentando em alguma medida uma continuidade em relação ao proposto no PCN Pluralidade Cultural, afirma a necessidade de uma educação pautada nos estudos das relações multiétnicas que formam o Brasil:

É importante destacar que não se trata de mudar um foco etnocêntrico marcadamente de raiz europeia por um africano, mas de ampliar o foco dos currículos escolares para a diversidade cultural, racial, social e econômica brasileira. Nesta perspectiva, cabe às escolas incluir no contexto dos estudos e atividades que proporciona diariamente também as contribuições histórico-culturais dos povos indígenas e dos descendentes de asiáticos, além das de raiz africana e europeia. É preciso ter clareza que o Art.26a, acrescido à Lei 9.394/1996, provoca bem mais do que inclusão de novos conteúdos, exige que se repensem relações étnico-raciais, sociais, pedagógicas, procedimentos de ensino, condições oferecidas para aprendizagem, objetivos tácitos e explícitos da educação oferecida pelas escolas. (BRASIL, 2004, p. 17)

A estruturação do texto das Diretrizes apresenta duas partes, relativamente distintas, mas organicamente articuladas. $\mathrm{Na}$ primeira, está 
localizado o conjunto de justificativas e fundamentos relativos à Lei 10.639/03, tais como: a necessidade da promoção de uma "reeducação das relações entre negros e brancos" (BRASIL, 2004, p. 7) como alicerce para um convívio democrático entre os Brasileiros; a demanda histórica da população afrodescendente pela implementação de políticas de reparação e valorização de sua história, cultura e identidade; a demanda da comunidade afro-brasileira pela valorização e afirmação de direitos, especialmente no que diz respeito à educação; a necessidade de desconstrução do mito da democracia racial; o reconhecimento e o respeito às pessoas negras, à sua ascendência africana e à sua capacidade histórica de luta e resistência, etc.

$\mathrm{Na}$ segunda parte do documento, são apresentadas orientações e determinações de caráter normativo, expressas por meio de três princípios: a consciência política e histórica da diversidade brasileira, o fortalecimento de identidades e de direitos (incluindo o desencadeamento do processo de afirmação de identidades, de historicidade negada ou distorcida) e as ações educativas de combate as discriminações. Tais princípios em seu conjunto almejam que se ultrapasse a perspectiva de que a história africana e afrobrasileira limite-se à inclusão curricular de novos conteúdos, mas sim, que se fomente, por meio da evocação da experiência histórica africana e afrobrasileira, possibilidades da construção de ações pedagógicas de combate ao racismo e as discriminações direcionadas para a reflexão e a prática de relações étnico-raciais que tenham como finalidade a igualdade racial.

Neste sentido,

O ensino de História e Cultura Afro-Brasileira e Africana, [...] envolverá articulação entre passado, presente e futuro no âmbito de experiências, construções e pensamentos produzidos em diferentes circunstâncias e realidades do povo negro. É um meio privilegiado para a educação das relações étnico-raciais e tem por objetivos o reconhecimento e valorização da identidade, história e cultura dos afro-brasileiros, garantia de seus direitos de cidadãos, reconhecimento e igual valorização das raízes africanas da nação brasileira, ao lado das indígenas, europeias, asiáticas (BRASIL, 2004, p. 20).

Outro aspecto importante nas Diretrizes Curriculares em discussão é a seleção de algumas disciplinas escolares como lugares privilegiados para o 
desenvolvimento da política educacional em foco. De acordo com o próprio documento:

\begin{abstract}
O ensino de História e Cultura Afro-Brasileira e Africana, a educação das relações étnico-raciais, tal como explicita o presente parecer, se desenvolverão no cotidiano das escolas, nos diferentes níveis e modalidades de ensino, como conteúdo de disciplinas, particularmente, Educação Artística, Literatura e História do Brasil, sem prejuízo das demais, em atividades curriculares ou não, trabalhos em salas de aula, nos laboratórios de ciências e de informática, na utilização de sala de leitura, biblioteca, brinquedoteca, áreas de recreação, quadra de esportes e outros ambientes escolares (BRASIL, 2004, p.21).
\end{abstract}

No contexto pós-lei 10639/03, observa-se, sobretudo no campo de ensino de história, o aparecimento de uma produção inicial que se posiciona favorável à inclusão da temática afro-brasileira, na perspectiva da positivação segundo os dispositivos legais ${ }^{1}$. Entretanto, essa produção chama atenção para o risco de leituras do passado afro-brasileiro, no contexto escolar, que possam levar a simplificações da experiência histórica vivenciada pelos sujeitos em questão, bem como para o risco da associação entre tais simplificações às perspectivas muito criticadas voltadas a construção do conhecimento da história escolar, ancorado em interpretações do passado, dirigidas para a heroicização de personagens, a reificação de episódios e a busca de autenticidades, origens, raízes e essencialismos.

Um último aspecto da obrigatoriedade do ensino da história e cultura africana e afro-brasileira como política educacional que destacamos relacionase à perspectiva acerca do dever de memória em torno da experiência histórica afro-brasileira presente nas prescrições legais.

A noção de dever de memória refere-se a um conjunto de ações de reparação e reconhecimento por parte do Estado e da sociedade em que ambos buscam garantir a grupos vitimados por acontecimentos e processos opressivos e traumáticos ocorridos em algum momento, em determinada sociedade ou país, que suas memórias e histórias particulares não sejam esquecidas. Ao contrário, almeja-se que tais memórias devam ser lembradas e

\footnotetext{
${ }^{1}$ Ver Mattos (2003), Mattos; Abreu; Dantas e Moraes (2009), Pereira (2008).
} 
reconhecidas em sua especificidade, como parte constitutiva das histórias nacionais.

Segundo Heymann (2007),

a afirmação do dever de memória se refere, portanto, à ideia de que cada grupo social, outrora vítima e hoje herdeiro da dor, pode reivindicar não só o direito de celebrar seus mártires e heróis, mas também o reconhecimento pelos danos sofridos e alguma forma de reparação. Defender o dever de memória é, pois, afirmar a obrigação que tem um país de reconhecer o sofrimento imposto a certos grupos da população, sobretudo quando o Estado tem responsabilidade por esse sofrimento (HEYMANN, 2007, p. 21).

Heymann (2007) aponta que o que se observa, então, em linhas gerais, é a busca de reconhecimento e legitimidade por parte de grupos que, destacando-se da "comunidade nacional", passam a definir-se a partir de novas categorias, sejam elas étnicas, religiosas, de gênero, etc. Partindo desta constatação acerca das formas pelas quais grupos de pertencimentos identitários diversos apropriaram da noção de dever de memória, as Diretrizes Curriculares, apesar de não citar literalmente em seu texto tal noção, apresenta passagens em suas "Questões introdutórias" que buscam justificar as "Políticas de Reparações, de Reconhecimento e Valorização de Ações Afirmativas", reflexões sugestivas acerca da prerrogativa do não-esquecimento público sobre a experiência histórica afro-brasileira, assim como outros compromissos com esse grupo étnico-racial. De acordo com a normativa em discussão:

O parecer procura oferecer uma resposta, entre outras, na área da educação, à demanda da população afrodescendente, no sentido de políticas de ações afirmativas, isto é, de políticas de reparações, e de reconhecimento e valorização de sua história, cultura, identidade. [...] Propõe a divulgação e produção de conhecimentos, a formação de atitudes, posturas e valores que eduquem cidadãos orgulhosos de seu pertencimento étnico-racial [...] para interagirem na construção de uma nação democrática, em que todos, igualmente, tenham seus direitos garantidos e sua identidade valorizada [...]. A demanda por reparações visa a que o Estado e a sociedade tomem medidas para ressarcir os descendentes de africanos negros, dos danos psicológicos, materiais, sociais, políticos e educacionais sofridos sob o regime escravista, bem como em virtude das políticas explícitas ou tácitas de branqueamento da população, de manutenção de privilégios exclusivos para grupos com poder de governar e de influir na formulação de políticas, no pós-abolição. Visa também a que tais medidas se concretizem em iniciativas de combate ao racismo e a toda sorte de discriminações (BRASIL, 2004, p.10-11) 


\section{CONSIDERAÇÕES ACERCA DA NATUREZA DOS LIVROS DIDÁTICOS}

Os livros didáticos de história produzidos no Brasil, a partir das duas últimas décadas do século XX, apresentam um conjunto de mudanças que pode ser notado em uma dupla perspectiva. De um lado, alterações relativas à materialidade e aos aspectos formais ${ }^{2}$ do objeto cultural em questão, de outro, a inserção de novas temáticas e tipos de documentos históricos em sua composição, assim como a adoção de novas concepções de ensinoaprendizagem.

$\mathrm{Na}$ tentativa de compreensão desse conjunto de mudanças, parece haver um consenso entre os pesquisadores que tem o livro didático como objeto de estudo.

Um ponto de relativa convergência entre os estudiosos e teóricos do campo dos estudos sobre livros didáticos, tais como Bittencourt (1998; 2008), Munakata (1997), Chartier (1990; 1999), Choppin (2004), Miranda e Luca (2004), Bezerra e Luca (2007), Cassiano (2013), Luca (2009), Batista e Galvão (2009), entre outros, é a constatação da natureza polissêmica do manual escolar. De forma geral, o livro didático é considerado um objeto polissêmico, de difícil e complexa definição em decorrência de suas múltiplas faces e dimensões técnicas, pedagógicas e ideológicas e, em sua materialidade, da marca de interferência de vários sujeitos em sua produção, circulação e consumo.

Dito em outros termos, o livro didático tem, em sua constituição, as faces de mercadoria a partir de sua dimensão material associada à lógica da indústria cultural e do mercado editorial. O livro didático se constitui como suporte de conhecimentos escolares marcado pelos traços da cultura escolar e em diálogo com políticas públicas oficiais, propostas curriculares e de avaliação; como suporte de concepção de ensino-aprendizagem na configuração do que deve ser ensinado e apreendido em um saber escolar; e

\footnotetext{
${ }^{2}$ Para um panorama dessas mudanças, ver: Miranda e Luca (2004).
} 
veículo de um sistema de valores, pois se torna um lugar de difusão de pressupostos ideológicos e culturais historicamente construídos.

Outro elemento fundamental na discussão sobre a natureza dos livros didáticos relaciona-se aos processos de produção e de circulação desse material. Para que esses processos produtivos possam ser compreendidos, de forma satisfatória, que se considerem, nas investigações, as influências de diversos fatores imbricados na elaboração, circulação e consumo desses recursos pedagógicos. De acordo com a proposta investigativa formulada por Batista e Galvão (2009), ao definir as condições relacionadas à produção dos livros didáticos, eles apontam para a necessidade de se considerar os fatores de ordem econômica e tecnológica, de ordem educacional e pedagógica e de ordem social e política.

Assim, ao interrogarmos a produção, circulação e consumo dos livros didáticos no Brasil contemporâneo, é sugestivo considerarmos aspectos de ordem econômica e tecnológica, tais como o estágio de desenvolvimento tecnológico presente no maquinário da indústria editorial, o aparecimento de modelos de gestão do trabalho produtivo organizado pela articulação entre diversos profissionais, dedicados a diferentes aspectos e/ou etapas (editoração, design, produção textual, correção textual, estética, copyright, produção e seleção de imagens, dentre outros), voltados a elaboração de um mesmo produto final ao menor preço e no menor tempo possível. Ao lado desses, é importante também considerar o estudo dos direcionamentos, tendências e perspectiva do mercado especializado em produtos didáticos, fatores de ordem educacional, pedagógica, incluindo as concepções de ensinoaprendizagem em circulação nas escolas, as perspectivas hegemônicas nas áreas de referência das disciplinas escolares ${ }^{3}$ e as políticas públicas que incidem sobre o livro didático. Por fim, de ordem social e política, as políticas de apoio e incentivo à expansão do mercado editorial, o perfil social das demandas que se pretende atender, assim como sua relação com o produto demandado, etc. Diante dos aspectos elencados, uma conclusão antecipada

\footnotetext{
${ }^{3}$ A respeito das perspectivas historiográficas e pedagógicas em circulação nos livros didáticos de história em diferentes momentos históricos, consultar: Rocha; Reznik e Magalhães (2009).
} 
torna-se evidente: a de que para a produção, circulação e consumo ocorram, torna-se necessária a multiplicidade de intervenções de agentes sociais públicos e privados, em especial, o estado brasileiro, as editoras e os professores na elaboração dos recursos didáticos.

O papel das editoras no processo de mudança pelas quais passou a produção dos livros didáticos, e que contribuiu para a conformação do modelo do referido recurso pedagógico em vigência, encontra-se no espectro de preocupações de análise em Gatti Jr. (2004) e Munakata (1997). Assim, Gatti Jr. (2004), ao investigar como os livros didáticos de história foram modificados em sua forma (tamanho, cores, gramatura das folhas, etc.) e conteúdo (novas temáticas, incorporações de documentos históricos, etc.), bem como as alterações no processo produtivo propriamente dito (de autores individuais para equipes editoriais e de editoras familiares e regionais por editoras maiores, geralmente de expressão nacional), e Munakata (1997), ao problematizar o percurso de produção de livros didáticos e paradidáticos, esclarecem que, ao contrário de tempos anteriores, as obras produzidas a partir das décadas de 1970, não são mais resultados do trabalho de autores quase sempre isolados. Ao contrário, são resultantes do trabalho de uma ampla gama de profissionais especializados em diversas etapas da editoração e produção de impressos. Assim, em suas conclusões, Munakata (1997) aponta que os impressos didáticos produzidos pela indústria editorial são resultado da intervenção e diversos sujeitos em seu processo de feitura, tais como editores, autores, programadores visuais, ilustradores, revisores ortográficos, etc.

O argumento de que o livro, de forma geral, e o didático, especificamente, são artefatos culturais complexos em sua fabricação e comercialização é compartilhado entre os pesquisadores do campo, assim como há o compartilhamento da ideia de que "o livro como objeto da indústria cultural impõe uma forma de leitura organizada por profissionais e não exatamente pelo autor" (BITTENCOURT, 2004, p.71).

Outro aspecto central na produção dos livros didáticos em diversos países, especialmente no Brasil, a partir de meados dos anos 1930, é a estreita relação 
entre estado e produção didática ${ }^{4}$. A investigação histórica acerca dos livros didáticos tem evidenciado que tal produção desenvolve-se, em graus diversos, na articulação das demandas e determinações do poder político educacional. A criação do manual didático como suporte de conteúdos a serem ensinados em contexto escolar, articula-se à institucionalização e a ampliação dos sistemas educacionais no ocidente em meados do século XIX (CHOPPIN, 2004). Considerando-se que os países ocidentais passaram por um processo de relativa escolarização a partir do século XIX, os manuais que portavam os valores, os currículos, as funções designadas pelos estados nacionais ganharam importância na cultura escolar que emergia.

Circe Bittencourt (2008), ao pesquisar o livro didático de história produzido no Brasil, entre 1820 e 1910, constata que, simultaneamente a essa produção, ocorria o processo de institucionalização das primeiras versões oficiais da história nacional. A autora explica que as obras didáticas eram espaços privilegiados por alguns historiadores para a circulação em espaço escolar de suas leituras sobre o passado nacional.

Apple (1995) lembra que os livros são simultaneamente suportes materiais elementares em contexto escolar, portadores e representantes da cultura legitimada socialmente.

São os livros didáticos que estabelecem grande parte das condições materiais para o ensino e a aprendizagem nas salas de aula de muitos países através do mundo [...] são os textos destes livros que frequentemente define qual é a cultura legítima a ser transmitida. (APPLE, 1995, p.81)

O livro didático, como suporte transmissor da cultura hegemônica e do saber oficialmente prescrito, não se coloca em lugar pacífico. Ao contrário, coloca-se como resultado de diferentes tensões políticas, econômicas e culturais. Nos dizeres de Apple (1997),

\footnotetext{
${ }^{4}$ A cronologia das ações do governo brasileiro em relação ao livro didático informa que, embora a estruturação de um programa de avaliação determinante dos processos de compra seja algo relativamente recente, o estabelecimento de uma política pública para o livro didático remonta ao Estado Novo, quando se instituiu, pela primeira vez, uma Comissão Nacional de Livros Didáticos (CNLD), cujas atribuições envolviam o estabelecimento de regras para a produção, compra e utilização do livro didático.
} 


\begin{abstract}
Eles são, ao mesmo tempo, o resultado de atividade políticas, econômicas e culturais de lutas e concessões. Eles são concebidos, projetados e escritos por pessoas reais, com interesses reais. Eles são publicados dentro dos limites políticos e econômicos de mercados, recursos e poder. E o que significam os livros e seu uso envolve disputas em comunidades com compromissos evidentemente diferentes e também entre professores/as e aluno/as (APPLE, 1997, p.74).
\end{abstract}

Neste sentido, a produção didática torna-se território de luta simbólica em torno do que se deve ser selecionado como válido a ser ensinado para os mais jovens. Especialmente no caso dos livros didáticos de história, em que há a disputa pelo controle das narrativas do passado, como sendo campos frutíferos para a proposição de pertencimentos identitários. Como destaca Luca (2009):

\begin{abstract}
É preciso reconhecer que os espaços de circulação dos livros didáticos são, pelo menos em tese, bem mais específicos que os literários, e que neles o Estado desempenha papel essencial, pois é da sua competência definir os contornos do aparato escolar, sobre o qual tem o poder de legislar, formular propostas pedagógicas, impor conteúdos, programas curriculares e normas para os profissionais que nele atuam. E é justamente a existência de uma política educacional que cria um público cativo (os alunos), que demanda livros específicos (escolares), que devem ser escritos (autores) e produzidos (editores) de acordo com os programas e objetivos prescritos e reconhecidos como relevantes (Estado) pelo menos por parte da sociedade (LUCA, 2009, p.153).
\end{abstract}

A produção didática como território de luta simbólica em torno da proposição de pertencimentos identitários, no que tange a tais pertencimentos associados ao negro no Brasil, um tema diretamente relacionado com a valorização de personagens negros, vem sendo estudada e denunciada, especialmente, a partir da última década do século $X X$, como um espaço de desigualdade racial e discriminação, e, portanto, como lugar de reprodução de práticas de racismo na sociedade brasileira ${ }^{5}$.

Acrescido a isso, o estado, além de controlar o currículo, sobretudo na definição das disciplinas ou matérias a serem ensinadas, e exercer o poder

\footnotetext{
${ }^{5}$ Consultar: Silva (2008), Rosemberg; Silva e Bazilli (2003), Silva (1995).
} 
sobre a circulação do livro didático, tem se constituído como um importante comprador dessa modalidade específica de suporte pedagógico.

As intervenções do estado, conforme já apontado, não configuram necessariamente uma novidade. No entanto, com a criação do Programa Nacional do Livro Didático $\left(\mathrm{PNLD}^{6}\right)$, em 1985, e, especialmente, a partir da adoção da avaliação das obras didáticas implementadas a partir de 1996, provocaram transformações positivas na forma e nos conteúdos dos livros didáticos. Também contribuíram para a criação de fatores de estabilidade presente na configuração do livro didático, dentre elas, a obrigatoriedade de ser composto pelo manual do professor e pelo livro do aluno, reunidos na forma de uma coleção produzida com vistas ao uso sequencial ao longo de um grau de ensino. Diante de tal contexto, no Brasil contemporâneo, a caracterização do livro didático não pode ser feita descolada das políticas públicas de distribuição e avaliação dos livros. Com a criação do Programa Nacional do Livro Didático (PNLD), pela ação do Ministério da Educação, o governo brasileiro transformou-se no maior comprador de livros do mundo. A indústria do livro no país tem no manual escolar seu segmento majoritário nos aspectos quantitativos de vendas, faturamento e volume de exemplares.

Por fim, não podemos perder de vista a dinâmica mercadológica em torno da produção didática. Essa reflexão torna-se importante, pois o livro, apesar de pertencente ao universo da cultura escolar, não se restringe a essa característica, ao contrário, como objeto multifacetado, o manual escolar é, também, uma mercadoria submissa às determinações do mercado e, portanto, tem que se adaptar às suas imposições. Como nos alerta Bittencourt:

O livro didático é, antes de tudo, uma mercadoria, um produto do mundo da edição que obedece à evolução dos técnicos de fabricação e comercialização pertencente à lógica do mercado. Como mercadoria, ele sofre interferências variadas em seu processo de fabricação e comercialização. E completa, afirmando que o livro didático é um importante veículo portador de um sistema de valores, de uma ideologia, de uma cultura (BITTENCOURT, 1998, p. 71-72).

\footnotetext{
${ }^{6}$ Através do PNLD, o estado brasileiro passou a distribuir livros didáticos de todas as disciplinas escolares para os alunos das escolas públicas da educação fundamental, consolidando-se assim uma política universal e gratuita de distribuição de livros didáticos. Posteriormente, em 2003, com a criação do Programa Nacional do Livro Didático para o Ensino Médio (PNLEM), política semelhante se estende ao ensino médio.
} 


\section{ESTRATÉGIAS DE VALORIZAÇÃO DE PERSONAGENS NEGROS EM LIVROS DIDÁTICOS DE HISTÓRIA}

O universo de obras selecionadas para a análise foi composto por três coleções didáticas de história, dos anos finais do ensino fundamental, aprovadas pela primeira vez na edição do PNLD 2008 e reeditadas no PNLD 2011. Trata-se das seguintes obras: "História - Das Cavernas ao Terceiro Milênio" de autoria de Myriam Becho Mota e Patrícia Ramos Braick (Editora Moderna); "História em Projetos" de Maria da Conceição Carneiro de Oliveira, Carla Miucci Ferraresi e Andréa Paula dos Santos (Editora Ática) e "História, Sociedade e Cidadania" do autor Alfredo Boulos Júnior (Editora FTD).

Além da referida aprovação das obras no PNLD 2008 e 2011, a escolha das coleções também considerou a forma pela qual a temática afrodescendente é abordada pelas obras. De acordo com o Guia do Livro Didático 2011, os livros didáticos aprovados foram definidos em duas categorias no que tange as formas de abordagem das temáticas indígenas e negra, a informativa e a crítico-reflexiva.

Pela perspectiva informativa, entende-se que seja aquela que aborda a temática étnico-racial

de modo vinculado, sobretudo, à abordagem dos conteúdos históricos previstos, sem que tal tratamento seja, necessariamente, vinculado a uma reflexão crítica integral e voltada à problematização do tempo presente ou mesmo ao tratamento longitudinal e complexo das relações temporais, seja da História das populações indígenas, seja da História da África e situação dos afrodescendentes no Brasil. Com isso, predomina, para o estudante, uma relação de possibilidade de aquisição informativa e uma condição de análise de tais temáticas ainda, predominantemente, de modo vinculado direta ou indiretamente à cronologia eurocêntrica (BRASIL, 2010, p. 24).

A abordagem crítico-reflexiva busca superar a simples incorporação de novos conteúdos relacionados às histórias africana, afro-brasileira e indígena e/ou o tratamento meramente informativo e factual de tais temáticas históricas. Ao contrário, tal abordagem organiza-se em "uma problematização complexa 
entre passado e presente no tocante aos assuntos envolvidos nas exigências e prescrições legais" (BRASIL, 2010, p. 24). Neste sentido, suas finalidades buscam a constituição pelo aluno

\footnotetext{
de um quadro reflexivo mais amplo e denso no tocante à compreensão das contradições, das mudanças e continuidades históricas, da ação dos sujeitos e da emergência de atitudes derivadas de uma consciência histórica capaz de engendrar a ação social (BRASIL, 2010, p. 24).
}

Assim, optamos por investigar somente as coleções que traziam um tratamento crítico-reflexivo para a temática afrodescendente como uma possibilidade que abordagem renovada sobre a experiência histórica afrobrasileira em páginas didáticas.

Nas obras investigadas, as estratégias de valorização de personagens afro-brasileiros ocorrem em diferentes lugares na ordem interna dos livros (texto básico, textos complementares), assim como nas atividades propostas e com finalidades distintas.

Os personagens históricos negros no contexto do pós-abolição brasileiro presentes nos conteúdos explícitos (CHERVEL, 1990) são lembrados em diferentes momentos históricos em todas as coleções analisadas. Os participantes da Revolta da Vacina, da Revolta da Chibata, dos movimentos culturais afro-brasileiros e do processo de redemocratização são ilustrativos nesse sentido.

Tomando o tema histórico da Revolta da Chibata como objeto de exemplificação, a perspectiva da regularidade em relação a esse acontecimento histórico, pode ser compreendida por três aspectos. Um, pela repetição da seleção do acontecimento histórico em todas as coleções, em suas duas edições, um segundo, pela forma como sua abordagem ocorre e, por fim, em relação ao lugar reservado ao tema na organização interna dos livros.

O levante dos marinheiros acontecido no Rio de Janeiro em 1910, conhecido como Revolta da Chibata, nas três coleções, encontra-se localizado 
no texto-síntese dos capítulos e sua presença, organizada por meio de texto didático e da reprodução de imagens de época ${ }^{7}$.

Em relação aos capítulos em que a Revolta da Chibata compõe um dos temas, esses, geralmente, voltam-se ao ensino-aprendizagem de conteúdos curriculares, contextualizados na chamada República Oligárquica (1889-1930).

Outro ponto de convergência apresentado nas obras, ao tratarem da revolta no texto-síntese, é a construção do sentido em torno do episódio. Em todas as coleções, a interpretação do movimento rebelde volta-se à compreensão do ocorrido, associando-o a conjuntura e a questões de seu próprio tempo. A rebelião dos marinheiros é interpretada como uma das revoltas que compõe um quadro mais amplo de resistência popular durante os primeiros anos da República. Assim, associada a movimentos como o da Revolta da Vacina, as Guerras de Canudos e de Contestado, o levante dos marinheiros é interpretado como um dos episódios de reação ao projeto de Brasil moderno, almejado e executado pelas elites nacionais, que pressupunha a exclusão dos grupos populares de tais projetos.

Apesar do tema sobre a Revolta da Chibata ser tratado em diferentes lugares nos livros didáticos, é no texto principal que sua apropriação como conteúdo curricular ocorre de forma mais assertiva. A exposição textual, em todas as coleções, organiza-se quase que por meio de uma narrativa padrão, que evidencia as motivações, os encaminhamentos realizados durante 0 processo do levante, as reivindicações dos amotinados e o desfecho da revolta. Essas informações apontam e contribuem para uma interpretação do evento em que se faz uso do passado, considerando relevantes questões históricas relativas ao próprio tempo do acontecimento como conteúdo a ser aprendido pelos alunos. É interessante perceber que a exposição construída para esse acontecimento histórico sugere uma padronização da revolta, com finalidades escolares, compartilhada pelas três coleções.

Ainda sobre a revolta dos marinheiros, dois movimentos de interpretação em relação a tal acontecimento foram fundamentais para pesquisa,

\footnotetext{
${ }^{7}$ Boulos Júnior (2006d, p. 77), Braick e Mota (2006d, p. 44), Oliveira; Ferraresi e Santos (2006c, p.33).
} 
relacionados diretamente com as representações em circulação sobre o mesmo.

O primeiro dos movimentos diz respeito à dinâmica étnico-racial considerada como sendo parte das motivações da revolta, apesar de repetidas vezes ser apontada pela historiografia dedicada ao tema como aspecto de relevo para a compreensão da revolta ${ }^{8}$. Essa perspectiva de entendimento da revolta é, majoritariamente, suprimida da narrativa didática, sugerindo uma interpretação do referido evento histórico como uma resposta estritamente social para a situação de exclusão vivenciada pelos oficiais de baixa patente da marinha brasileira, apartada da perspectiva étnico-racial. As justificativas construídas para a ação dos marinheiros estava associada às seguintes condições:

Comida ruim, salários baixos, trabalhos pesados, disciplina despótica, castigos frequentes. Era essa a situação na Marinha brasileira do início do Período Republicano. A Revolta da Chibata, portanto, foi um movimento pela 'abolição da escravatura' nessa instituição (BRAICK; MOTA, 2006d, p. 44).

Marinheiros de dois dos mais importantes navios da Marinha (os encouraçados Minas Gerais e São Paulo) revoltaram-se, exigindo o fim dos castigos corporais e melhorias na alimentação da tripulação. Os castigos corporais já eram legalmente proibidos desde o fim da escravidão, mas na prática continuavam ocorrendo. Esse levante foi liderado por João Cândido Felisberto, filho de ex-escravos. Os 2.379 revoltosos se apoderaram de embarcações de guerra e mantiveram os canhões apontados para a capital da República. O Congresso Nacional, reunido às pressas, prometeu a extinção dos castigos corporais, o que fez cessar o levante (OLIVEIRA; FERRARESI; SANTOS, 2006c, p.33).

[...] exigiram do presidente Hermes da Fonseca o fim do castigo da chibata e de outros castigos físicos, o aumento dos soldos e a anistia para os marinheiros rebelados. (BOULOS JÚNIOR, 2006d, p.77).

O sentido construído para a revolta nas obras investigadas, ao considerarmos os motivos para a revolta elencados pelos próprios livros didáticos, apontam indícios que possibilitam a leitura de que a Revolta da Chibata foi exclusivamente uma ação de reação às condições sociais e

\footnotetext{
${ }^{8}$ Ver: Nascimento (2008).
} 
humanitárias pelas quais os marinheiros de baixa patente passavam, que, muito embora tenha sido protagonizado majoritariamente por negros e mulatos, o pertencimento racial de seus participantes não é selecionada como informação a ser lembrada no tempo presente.

Em contraposição à perspectiva hegemônica da não associação do referido evento histórico à questão do pertencimento étnico-racial de seus participantes, verifica-se em uma única passagem, descrita na legenda de uma foto dos participantes da revolta, a vinculação dos marinheiros a algum pertencimento racial. A legenda dialoga com o leitor a partir da seguinte sugestão:

\begin{abstract}
repare o grande número de afrodescendentes entre os marinheiros; por isso, alguns historiadores dizem que a existência da chibata no Código Disciplinar da Marinha era uma manifestação de preconceito. Os oficiais da Marinha pertenciam, em sua maior parte, a famílias ricas, brancas e poderosas, que havia bem pouco tempo tinham a seu serviço negros e mestiços, na condição de escravos ou libertos. (BOULOS JÚNIOR, 2009d, p.75).
\end{abstract}

Apesar da incorporação da legenda no livro aprovado no edital do PNLD 2011, cabe ressaltar que, o texto principal, no qual há o tratamento da Revolta da Chibata, não sofreu alteração em relação à edição anterior, em que o caráter étnico-racial dos participantes não é mencionado.

Outro aspecto identificado nas abordagens relaciona-se à representação dos sujeitos participantes da revolta. A narrativa construída para contar a história da rebelião busca valorizar a atuação coletiva do grupo rebelde, sem, contudo, preterir sua liderança, evidenciando que, conquanto, a participação coletiva tenha sido o motor da resistência, a figura da liderança é lembrada e digna de rememoração ${ }^{9}$.

Esse modo de recordar a Revolta da Chibata é compartilhado por todas as coleções analisadas. Assim, além da menção a João Candido nos textos didáticos, são incorporadas imagens que colocam esse sujeito histórico em foco e são construídas legendas com informações a seu respeito.

\footnotetext{
${ }^{9}$ Boulos Júnior (2006d, p. 67 e 75), Braick e Mota (2006d, p.52), Oliveira; Ferraresi e Santos (2006c, p.33).
} 
Outra estratégia comum a todas as coleções no tratamento dispensado aos personagens negros no contexto pós-abolição é a sugestão da realização de atividades em que sujeitos afro-brasileiros sugeridos como objetos da construção de conhecimento pelos alunos.

A pesquisa escolar e a produção de textos acerca de sujeitos afrobrasileiros aparecem como uma maneira de dar visibilidade ao tema em foco de forma recorrente em diferentes coleções ${ }^{10}$. Na coleção "História: sociedade e cidadania", em suas duas edições e em diferentes volumes, observa-se o uso recorrente desse tipo de estratégia didática nas atividades propostas. Passagens ilustrativas, neste sentido, são observadas no livro do sexto ano, em exercício em que se pede ao aluno que pesquise, individualmente, a biografia de mulheres negras ${ }^{11}$ e redija um texto sobre uma delas.

De forma similar, no volume do sexto ano da mesma coleção, em suas duas edições, em um capítulo organizado para o ensino-aprendizagem da história africana anterior ao século XVI, portanto, sem conexão direta com a história afro-brasileira a partir dos anos finais do século XIX até a contemporaneidade. Desta forma, no capítulo 8 "A Núbia e o Reino de Kush", em atividade de aprofundamento, pede-se:

No Brasil de hoje, há um número considerável de mulheres negras conhecidas por sua atuação no campo da cultura (teatro, cinema, música, literatura), do esporte e da política. Escolha uma dessas mulheres e escreva uma minibiografia sobre ela. llustre seu trabalho com fotografias, colagens ou desenhos (BOULOS JÚNIOR, 2009a, p. 137).

É interessante percebermos também a visibilidade dada a personagens negros em atividades que buscam articular finalidades formativas voltadas para fruição estética e o conteúdo histórico de acontecimentos e/ou sujeitos históricos. Como podemos observar na passagem a seguir, extraída da Coleção "História. Das cavernas ao terceiro milênio", é solicitado ao estudante que conheça a música e a letra de determinada canção e retire da letra fragmentos que dizem respeito ao acontecimento histórico mencionado na

\footnotetext{
${ }^{10}$ Boulos Júnior (2009c, p. 56), Braick e Mota (2006h, p. 52).

${ }^{11}$ Boulos Júnior (2009a, p. 137).
} 
música, dessa forma, em uma atividade de "aprofundamento do estudo" pedese o que se segue aos alunos:

\begin{abstract}
A figura de João Cândido, líder da Revolta da Chibata, inspirou uma canção de João Bosco e Aldir Blanc, intitulada 'O mestre-sala dos mares'. Procure conhecer a música e a letra da canção. Depois, escreva em seu caderno os trechos em que os autores fazem referência ao marinheiro rebelde (BRAICK; MOTA, 2006h, p.52).
\end{abstract}

A mobilização de conhecimentos adquiridos pelos alunos em tempos e espaços não escolares é um aspecto relacionado à aprendizagem ainda pouco explorado como recurso, no tratamento do pós-abolição, como conteúdo curricular.

Somente na coleção "História, sociedade \& cidadania", na edição de 2009, são identificadas apropriações nessa natureza. No entanto, a despeito da baixa incorporação desse tipo de proposta de aprendizagem, consideramos relevante a análise das abordagens identificadas, por dois motivos. O primeiro relaciona-se à emergência desse tipo de perspectiva de abordagem e, na edição anterior das obras, ela não foi utilizada. O segundo deve-se ao fato das abordagens terem sido construídas como estratégias para a introdução de capítulos, selecionadas para comporem páginas introdutórias de dois capítulos, um lugar de destaque na organização interna dos livros.

A página que introduz o capítulo "Africanos no Brasil: dominação e resistência", presente no volume do oitavo ano, apresenta um conjunto de fotografias de personalidades afro-brasileiros contemporâneos e atuantes em diferentes campos, como o cultural, político institucional, acadêmico, etc. Dentre eles, Marcelo Falcão (cantor, músico e compositor do grupo “O Rappa”); Joaquim Barbosa (jurista, ex-procurador da República e ex-ministro e presidente do Supremo Tribunal Federal); Sueli Carneiro (filósofa, ativista política, doutora em Educação e diretora da ONG Geledés - Instituto da Mulher Negra); Lázaro Ramos (ator, apresentador, cineasta e escritor de literatura infantil); Milton Santos (geógrafo, especialista em estudos de urbanização do Terceiro Mundo e professor universitário, falecido em 2001); Paulo Paim (ex-sindicalista, ex-deputado federal e senador da República pelo 
estado do Rio Grande do Sul); Leci Brandão (intérprete, compositora, deputada estadual em São Paulo), acompanhado por um grupo de questões que tem como objetivo provocar os estudantes a identificar quem são os representados nas imagens e suas atuações na sociedade brasileira.

As questões que acompanham as imagens pedem ao aluno que,

observe as fotos destas personalidades. O que ela tem em comum? Quais você conhece? Você tem acompanhado a contribuição delas à vida social brasileira? Teste seus conhecimentos: escreva no caderno o nome e o trabalho que cada uma desenvolve. (BOULOS JÚNIOR, 2009c, p.56)

É sugestivo percebermos que a página introdutória busca motivar o ingresso em conteúdos que tratam da trajetória histórica dos negros no Brasil, na extensão temporal do início do tráfico de africanos escravizados para América Colonial Portuguesa até a contemporaneidade. Porém, mesmo que os sujeitos representados façam parte do conteúdo em questão, nenhuma das questões sugeridas, que acionam os conhecimentos antecipados dos estudantes, aponta para o conteúdo a ser aprendido.

Os conhecimentos prévios dos alunos são mobilizados de forma factual e com o objetivo de identificar os sujeitos históricos em destaque, assim como sua atuação no mundo social, sem nenhuma reflexão histórica, tal como pressupõe a dinâmica elaborada para o conteúdo do capítulo. Contudo, a despeito dessa consideração, nessa passagem, é possível perceber um substancial cuidado editorial com a abertura do capítulo, que evidencia, do ponto de vista visual, mas com nítidos impactos pedagógicos, a intervenção de participantes no processo de produção do livro didático para além do autor do texto didático, possivelmente relacionados com os setores editoriais e gráficos da editora, responsáveis pela seleção das imagens, assim como a preocupação em evidenciar a diversidade de sujeitos históricos, afro-brasileiros dignos de serem lembrados como representativos em um duplo sentido, na perspectiva de gênero e em relação aos diversos setores da sociedade brasileira. 


\section{CONSIDERAÇÕES FINAIS}

A discussão acerca de como a valorização de personagens negros no contexto pós-abolição brasileiro vem sendo tratada como conteúdo curricular nos livros didáticos de história produzidos posteriormente a Lei 10.639/03, tornou possível a percepção sobre a necessidade de superação de pesquisas que buscam analisar as representações de africanos e afro-brasileiros em livros didáticos de história circunscritos ao contexto da escravidão. Apesar de a escravidão ser um dos processos centrais para a configuração em perspectiva histórica da identidade, da memória e da história afro-brasileira, em seus efeitos sociais, políticos, identitários, culturais e econômicos, outros aspectos da experiência histórica afro-brasileira devem ser objeto de investigações acadêmicas, uma vez que muito pouco ainda é conhecido sobre as abordagens em circulação nos artefatos culturais voltados para o ensino-aprendizagem no contexto posterior a Lei 10.639/03. Neste sentido, o movimento de dar visibilidade à heterogeneidade temática relativa à experiência histórica afro-brasileira, não limitada à escravidão, identificada nos livros didáticos analisados, mostra-se como um dos possíveis caminhos para as alterações curriculares iniciadas pela Lei 10.639/03.

A ausência de perspectiva heroicizante nas abordagens dispensadas aos personagens negros é outro aspecto importante a ser ressaltado. Tal importância relaciona-se ao tratamento crítico e reflexivo direcionado aos personagens afrobrasileiros, o que aponta para possível ruptura com uma concepção sujeito histórico heroico e idealizado que povoavam (e, em menor grau, ainda povoam) as páginas didáticas da história.

Outra consideração importante para discussão aqui tratada é o tratamento pedagógico dado aos personagens negros. A elaboração de atividades que propõem o desenvolvimento de pesquisas e de produção de textos sobre tais sujeitos é uma estratégia didática fundamental para o relacionamento ativo dos alunos com a história e memória afro-brasileira.

Em linhas gerais, verificamos que a produção de materiais didáticos analisada, apesar dos limites, aponta para um tratamento significativo acerca da 
visibilidade dada a personagens negros como estratégia voltada para a implementação da política pública que visa reconhecer e valorizar da história e cultura afro-brasileira e africana, caminho necessário para a uma educação das relações étnico-raciais entre nós, brasileiros.

\section{LUCIANO MAGELA ROZA}

Doutor em Educação pela Universidade Federal de Minas Gerais - UFMG. Professor adjunto na Universidade Federal dos Vales do Jequitinhonha e Mucuri - UFVJM.

\section{REFERÊNCIAS}

APPLE, M. Cultura e comércio do livro didático. In: APPLE, M. Trabalho docente e textos. Porto Alegre: Artes Médicas, 1995, p. 81-105.

. Conhecimento oficial: a educação democrática numa era conservadora. Rio de Janeiro: Vozes, 1997.

BATISTA, A. G.; GALVÃO, A. M. O. Livros escolares de leitura no Brasil: elementos para uma história. Campinas/SP: Mercado de Letras, 2009.

BRASIL. Congresso Nacional. Lei 10.639, de 9 de janeiro de 2003. Altera a Lei n. ${ }^{\circ} 9.394$, de 20 de dezembro de 1996, que estabelece as diretrizes e bases da educação nacional, para incluir no currículo oficial da Rede de Ensino a obrigatoriedade da temática "História e Cultura Afro-Brasileira", e dá outras providências. Diário Oficial [da] República Federativa do Brasil, Poder Executivo, Brasília, DF, p. 03, 24 jul. 2002. Seção 1.

. Diretrizes Curriculares Nacionais para a educação das relações étnicoraciais e para o ensino de história e cultura afro-brasileira e africana na Educação Básica. Ministério da Educação. Brasília: Secad, 2004.

. Guia de livros didáticos - PNLD 2011. Brasília: MEC/FNDE, 2010.

BEZERRA, H. G.; LUCA, T. R. Em Busca da qualidade - PNLD História - 1996 -2004. In: SPOSITO, M. E. B. (Org.) Livros Didáticos de História e Geografia. São Paulo: Cultura Acadêmica, 2007. p. 24-53.

BITTENCOURT, C. Ensino de História: fundamentos e métodos. São Paulo: Cortez, 2004. 
. Livros didáticos entre textos e imagens. In: BITTENCOURT, C. (org.).

O saber histórico na sala de aula. São Paulo: Contexto, 1998, p. 69-90.

2008.

. Livro didático e saber escolar (1810-1910). Belo Horizonte: Autêntica,

CASSIANO, C. C. F. O mercado do livro didático no Brasil do século XXI: a entrada do capital espanhol na Educação nacional. São Paulo: Unesp, 2013.

CHARTIER, R. A história cultural: entre práticas e representações. Rio de Janeiro: Bertrand Brasil; Lisboa (Portugal): Difel, 1990.

. Práticas de Leitura. São Paulo: Estação Liberdade, 1999.

CHERVEL, A. História das disciplinas escolares: reflexões sobre um campo de pesquisa. Teoria \& Educação, Porto Alegre, n. 2, 1990, p. 202-203.

CHOPPIN, A. História dos livros e das edições didáticas: sobre o estado da arte. Educação e Pesquisa, São Paulo, v. 30, n. 3, 2004, p. 549-566.

GATTI JÚNIOR, D. A escrita escolar da história: livro didático e ensino no Brasil (1970-1990). Bauru (SP)/Uberlândia (MG): Edusc/Edufu, 2004.

HEYMANN, L. Q. O "devoir de mémorie" na França contemporânea: entre memória, história, legislação e direitos. In: GOMES, A. C. Direitos e cidadania. Rio de Janeiro: FGV, 2007, p.15-43.

LUCA, T. R. Livro didático e estado: explorando possibilidades interpretativas. In: ROCHA, H. A.; REZNIK, L.; MAGALHÃES, M. S. (org.). A história na escola. Autores, livros e leituras. Rio de Janeiro: Fundação Getúlio Vargas, 2009, v. 1, p. 151-172.

MATTOS, $\mathrm{H}$. O ensino de história e a luta contra a discriminação racial no Brasil. In: ABREU, M.; SOIHET, R. (orgs.). Ensino de história: conceitos, temáticas e metodologias. Rio de Janeiro: Casa da Palavra, 2003, p. 127-136.

MATTOS, H. B.; ABREU, M.; DANTAS, C. V.; MORAES, R. Personagens negros e livros didáticos: reflexões sobre a ação política dos afrodescendentes e as representações da cultura brasileira. In: ROCHA, H. A. B. et al. (orgs.). A história na escola: autores, livros e leituras. Rio de Janeiro: Editora FGV, 2009, p. 299-320.

MIRANDA, S. R.; LUCA, T. R. O livro didático de história hoje: um panorama a partir do PNLD. Revista Brasileira de História, São Paulo, v. 24, n. 48, p. 123144, 2004. 
MUNAKATA, K. Produzindo livros didáticos e paradidáticos. 1997. 215 p. Tese (Doutorado em História e Filosofia da Educação) - Departamento de Educação, Pontifícia Universidade Católica, São Paulo, 1997.

NASCIMENTO, Á. P. Cidadania, cor e disciplina na revolta dos marinheiros de 1910. Rio de Janeiro: Mauad/Faperj, 2008.

PEREIRA, J. S. Reconhecendo ou construindo uma polaridade étnico identitária? Desafios do ensino de história no imediato contexto pós-lei 10.639. Revista Estudos Históricos. Rio de Janeiro, n. 41, p. 21-43, 2008.

ROCHA, H. A. B.; REZNIK, L.; MAGALHÃES, M. S. (org.). A história na escola: autores, livros e leituras. Rio de Janeiro: Editora FGV, 2009.

ROSEMBERG, F.; SILVA, P. V. B.; BAZILLI, C. Racismo em livros didáticos brasileiros e seu combate: uma revisão da literatura. Educação e Pesquisa, São Paulo, v. 29, n.1, 2003, p. 125-146.

SILVA, A. C. A discriminação do negro no livro didático. Salvador: Editora UNEB, 1995. 107 p.

SILVA, P. V. B. Racismo em livros didáticos: estudo sobre negros e brancos em livros de Língua Portuguesa. Belo Horizonte: Autêntica, 2008. 224 p.

\section{Livros consultados}

BOULOS JÚNIOR, A. História: sociedade e cidadania. $5^{a}$ série. São Paulo: FTD, 2006a.

. História: sociedade e cidadania. 6ª série. São Paulo: FTD, 2006b.

. História: sociedade e cidadania. $7^{a}$ série. São Paulo: FTD, 2006c.

. História: sociedade e cidadania. 8a série. São Paulo: FTD, 2006d.

. História: sociedade e cidadania. $6^{\circ}$ ano. São Paulo: FTD, 2009a.

História: sociedade e cidadania. $7^{\circ}$ ano. São Paulo: FTD, $2009 \mathrm{~b}$.

. História: sociedade e cidadania. $8^{\circ}$ ano. São Paulo: FTD, 2009c.

. História: sociedade e cidadania. $9^{\circ}$ ano. São Paulo: FTD, 2009d.

BRAICK, P. R.; MOTA, M. B. História. Das cavernas ao terceiro milênio: Dos primeiros seres humanos à queda do Império Romano. $5^{\text {a }}$ série. 2. ed. São Paulo: Moderna, 2006a. 
. História. Das cavernas ao terceiro milênio: Da formação da Europa medieval à colonização do continente americano. $6^{a}$ série. 2 . ed. São Paulo: Moderna, 2006b.

. História. Das cavernas ao terceiro milênio: Séculos XVIII e XIX: as fundações do mundo contemporâneo. $7^{a}$ série. 2. ed. São Paulo: Moderna, 2006c.

. História. Das cavernas ao terceiro milênio: Desafios do terceiro milênio. $8^{a}$ série. 2. ed. São Paulo: Moderna, 2006d.

História. Das cavernas ao terceiro milênio: Dos primeiros seres humanos à queda do Império Romano. $6^{\circ}$ ano. 2. ed. São Paulo: Moderna, 2006e. (impresso em 2009).

. História. Das cavernas ao terceiro milênio: Da formação da Europa medieval à colonização do continente americano. $7^{\circ}$ ano. 2. ed. São Paulo: Moderna, 2006f. (impresso em 2009).

História. Das cavernas ao terceiro milênio: Séculos XVIII e XIX: as fundações do mundo contemporâneo. $8^{\circ}$ ano. 2. ed. São Paulo: Moderna, 2006g. (impresso em 2009).

. História. Das cavernas ao terceiro milênio: Desafios do terceiro milênio. $9^{\circ}$ ano. 2. ed. (impressão revista). São Paulo: Moderna, 2006h. (impresso em 2009).

OLIVEIRA, M. C. C.; FERRARESI, C. M.; SANTOS, A. P. História em projetos. As primeiras culturas humanas, os primeiros impérios e as primeiras religiões monoteístas. $5^{a}$ série. São Paulo: Ática, 2006a.

. História em projetos. Velhos mundos e mundos novos: encontros e desencontros - do século XV ao XVIII. 6ª série. São Paulo: Ática, 2006b.

. História em projetos. O mundo do avesso: o embate entre novas e velhas ideias - do século XVII ao XIX. $7^{\text {a }}$ série. São Paulo: Ática, 2006c.

História em projetos. A encruzilhada dos mundos: consertos e

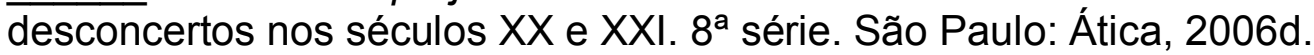

. História em projetos. As primeiras culturas humanas, os primeiros impérios e as primeiras religiões monoteístas. $6^{\circ}$ ano. 2. ed. São Paulo: Ática, 2009a.

História em projetos. Velhos mundos e mundos novos: encontros e desencontros - do século XV ao XVIII. $7^{\circ}$ ano. 2. ed. São Paulo: Ática, 2009b. 
Atos de Pesquisa em Educação - ISSN 1809-0354

Blumenau, v. 10, n.1, p.123-149, jan./abr. 2015

DOI: http://dx.doi.org/10.7867/1809-0354.2015v10n1p123-149

História em projetos. O mundo do avesso: o embate entre novas e velhas ideias - do século XVII ao XIX. $8^{\circ}$ ano. 2. ed. São Paulo: Ática, 2009c.

História em projetos. A encruzilhada dos mundos: consertos e desconcertos nos séculos XX e XXI. $9^{\circ}$ ano. 2. ed. São Paulo: Ática, 2009d. 